\title{
Corpus callosum in multiple sclerosis
}

\author{
R. O. BARNARD AND MARGARET TRIGGS \\ From the Department of Neuropathology, \\ The National Hospitals for Nervous Diseases, Maida Vale, London
}

SYNOPSIS A neuropathological study of 20 multiple sclerosis brains using celloidin-embedded slices was carried out to assess the extent of changes in the corpus callosum. Severe atrophy of the callosum was found in cases with marked hydrocephalus. Demyelination of the callosum varied in extent from slight involvement (with a few small plaques) to almost total myelin loss. A clinical history of mental deterioration was usual in the cases with severe callosal lesions, but no symptoms were recorded that indicated a specific disconnection syndrome. The ventricular enlargement noted in this series could not be explained either on the basis of obstruction to the flow of cerebrospinal fluid, or by the effects of shrinkage of the white matter.

In multiple sclerosis demyelination of the corpus callosum and atrophy (associated with ventricular enlargement) may be prominent pathological features, although they are seldom related to clinical symptoms. The possibility that these changes may be responsible for mental deterioration in this condition prompted our investigation into their frequency and severity.

We have studied a series of 20 cases of multiple sclerosis in which adequate brain sections were available to determine the extent of changes in the corpus callosum and the degree of ventricular enlargement. Cases with other coexisting lesions, such as tumours or infarctions, were excluded.

The patients, 10 of whom were male and 10 female, were aged from 21 to 65 years at the time of death, and the duration of their symptoms varied from two to 40 years. The pathological study was based on the examination of at least three levels of cerebral hemispheres cut in the coronal plane-for example, optic chiasm, mamillary bodies, red nuclei-embedded in celloidin, and stained for cells, myelin, axons, and glial fibres. In the majority of cases sections of all parts of the nervous system and of other organs were examined. Measurements of the maximum thickness of the corpus callosum were made at three levels and an estimate of the ventricular size was obtained by taking a transverse measurement of the whole brain and of the combined width of the lateral ventricles just below the corpus callosum. This ratio was determined merely in order to group the cases into those with great enlargement, moderate enlargement, and normal, or almost normal, ventricles (Table). In the first group (A) there were five cases with greatly enlarged lateral ventricles in all of which the corpus callosum was atrophic. Cases 1 and 2 presented a distinctive pathological picture of enormous lateral and third ventricles with only a very thin band of callosal fibres remaining (Fig. 1): the overall axonal loss in these greatly thinned tracts was considerable. In these two cases demyelination and gliosis in the cerebral hemispheres were not very severe. The nine cases with moderate ventricular enlargement (group B) shewed variation both in symptomatology and in degree of callosal atrophy. Cases 4 and 14 were characterized by severe demyelination and gliosis (Fig. 2) with large confluent zones resembling the lesions of Schilder's disease: in case 14 (Fig. 3) almost no myelin remained in the body of the corpus callosum, and there were signs of axonal destruction.

The other cases could be classified as 'typical' multiple sclerosis, with varying degrees of involvement of cerebrum, brain-stem, spinal cord, and optic nerves. Cortical plaques were found in many: they were usually small, involving the junction of cortex and white matter, and in no cases were there demonstrable changes in 
TABLE

DETAILS OF 20 CASES

\begin{tabular}{|c|c|c|c|c|c|c|c|c|c|c|}
\hline No. & $\begin{array}{l}\text { Path. } \\
\text { ref. } \\
\text { no. }\end{array}$ & $\operatorname{Sex}$ & $\begin{array}{l}\text { Age } \\
(y r)\end{array}$ & $\begin{array}{l}\text { Duration of } \\
\text { symptoms } \\
(y r)\end{array}$ & $\begin{array}{l}\text { Mental } \\
\text { changes }\end{array}$ & $\begin{array}{c}\text { Average size of } \\
\text { corpus callosum } \\
(\mathrm{mm})\end{array}$ & $\begin{array}{c}\text { Ratio of whole } \\
\text { brain to ventricles } \\
\text { (to } 1)\end{array}$ & $\begin{array}{c}\text { Callosal } \\
\text { demyelination }\end{array}$ & \multicolumn{2}{|c|}{$\begin{array}{l}\text { Callosal } \\
\text { axons }\end{array}$} \\
\hline \multicolumn{11}{|c|}{ A. Cases with greatly enlarged ventricles } \\
\hline 1 & 1996 & $\mathbf{M}$ & 42 & 12 & + & 1 & $2 \cdot 3$ & + & Loss & \\
\hline 2 & 2123 & $\mathbf{M}$ & 60 & 24 & + & 1 & $2 \cdot 6$ & + & Loss & \\
\hline 3 & 1851 & $\mathbf{F}$ & 65 & 4 & + & 3 & $2 \cdot 7$ & Slight & Normal & \\
\hline 4 & 1424 & $\mathbf{F}$ & 32 & 9 & + & 2 & $2 \cdot 7$ & + & Normal & \\
\hline 5 & 2033 & $\mathbf{F}$ & 54 & 21 & - & 2 & $2 \cdot 7$ & Slight & S1. loss & \\
\hline \multicolumn{11}{|c|}{ B. Cases with moderate ventricular enlargement } \\
\hline 6 & 2219 & $\mathbf{F}$ & 52 & 40 & + & 2 & 3.0 & + & Normal & \\
\hline 7 & 2037 & $\mathbf{F}$ & 40 & 9 & - & 3 & $3 \cdot 0$ & + & Normal & \\
\hline 8 & 2042 & $F$ & 57 & $30-35$ & - & 3 & $3 \cdot 0$ & Slight & Normal & \\
\hline 9 & 1753 & $\mathbf{M}$ & 54 & 24 & + & 2 & $3 \cdot 0$ & ++ & Normal & \\
\hline 10 & 1097 & $\mathbf{F}$ & 55 & 25 & + & 3 & 3.0 & + & Normal & \\
\hline 11 & 2157 & $\mathbf{M}$ & 21 & 4 & + & 2 & $3 \cdot 1$ & +++ & Marked & loss \\
\hline 12 & 1914 & $\mathbf{M}$ & 45 & 18 & + & 2 & $3 \cdot 2$ & ++ & S1. loss & \\
\hline 13 & 1568 & $\mathbf{M}$ & 56 & 18 & - & 3 & $3 \cdot \overline{3}$ & 0 & Normal & \\
\hline 14 & 2124 & $\mathbf{F}$ & 27 & 2 & + & 3 & $3 \cdot 3$ & $+++^{*}$ & Loss & \\
\hline \multicolumn{11}{|c|}{ C. Cases with normal ventricles or minimal enlargement } \\
\hline 15 & 2089 & $\mathbf{M}$ & 41 & 19 & - & 5 & $4 \cdot 0$ & Rare & S1. loss & \\
\hline 16 & 1858 & $\mathbf{M}$ & 48 & 15 & - & 3 & $4 \cdot 5$ & ++ & S1. loss & \\
\hline 17 & 1823 & $\mathbf{F}$ & 68 & 30 & - & $3-4$ & $4 \cdot 0$ & 0 & Normal & \\
\hline 18 & 1809 & $\mathbf{M}$ & 45 & 13 & - & $3-4$ & $4 \cdot 0$ & 0 & Normal & $\stackrel{\text { C }}{\complement}$ \\
\hline 19 & 1235 & $\mathbf{M}$ & 45 & 11 & - & 3 & $4 \cdot 0$ & + & Normal & $\bar{D}$ \\
\hline & 923 & $\mathbf{F}$ & 45 & 5 & - & 3 & $4 \cdot 5$ & 0 & Normal & $\stackrel{\mathscr{C}}{\longrightarrow}$ \\
\hline \multicolumn{6}{|c|}{ Average normal } & $4-5$ & $4 \cdot 0-5 \cdot 0$ & & & $\overline{0}$ \\
\hline
\end{tabular}

cortical neurones. In some patients, disabled by spinal cord involvement-for example, case 10the number of cerebral plaques was small (Fig. 4), but ventricular enlargement and mental

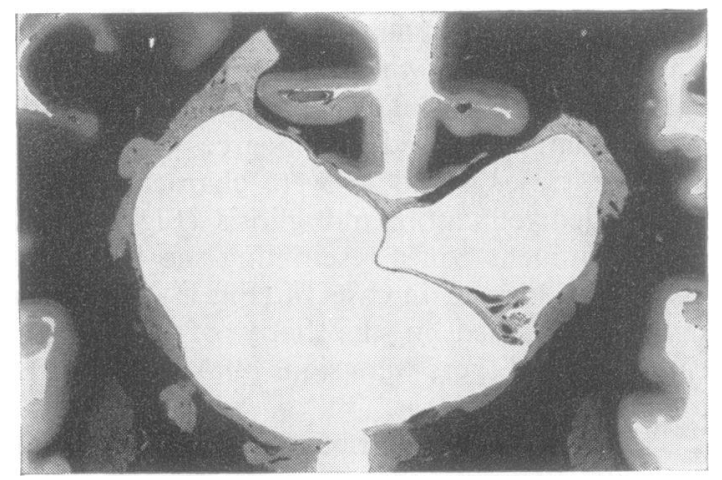

FIG. 1. Case 1. Massive ventricular enlargement and atrophy of the corpus callosum are conspicuous. The pathological findings provide no satisfactory explanation for this hydrocephalus. Heidenhain's myelin, $\times 1 \cdot 0$. deterioration were present. In no case was an aqueductal stenosis or obstruction to the outle of the fourth ventricle detected. In group $\mathrm{C}$ the were five cases with little or no ventricular $\vec{b}$ enlargement, in two of which slight or moderate demyelination of the corpus callosum was found.

Significant mental impairment had been observed on clinical examination in four out of five patients in group A, six out of nine in B, and in none of $\mathrm{C}$. In patients with a prolonged illness, mental symptoms did not appear as an early sign with the exception of case 12 .

\section{CASE 12}

This man was first seen at Maida Vale Hospital by the late Dr Redvers Ironside in 1955 when he was 30 years of age. His first symptoms had appeared four years earlier when he experienced transient blurring of vision in the right eye which cleared $₹$

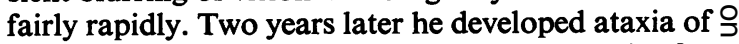
gait. His past history was remarkable only for $D$ exposure to stress of unusual degree. Removed from Jersey to an internment camp near Essen at the age of $N$ 16 years he suffered from the effects of violent injury, 


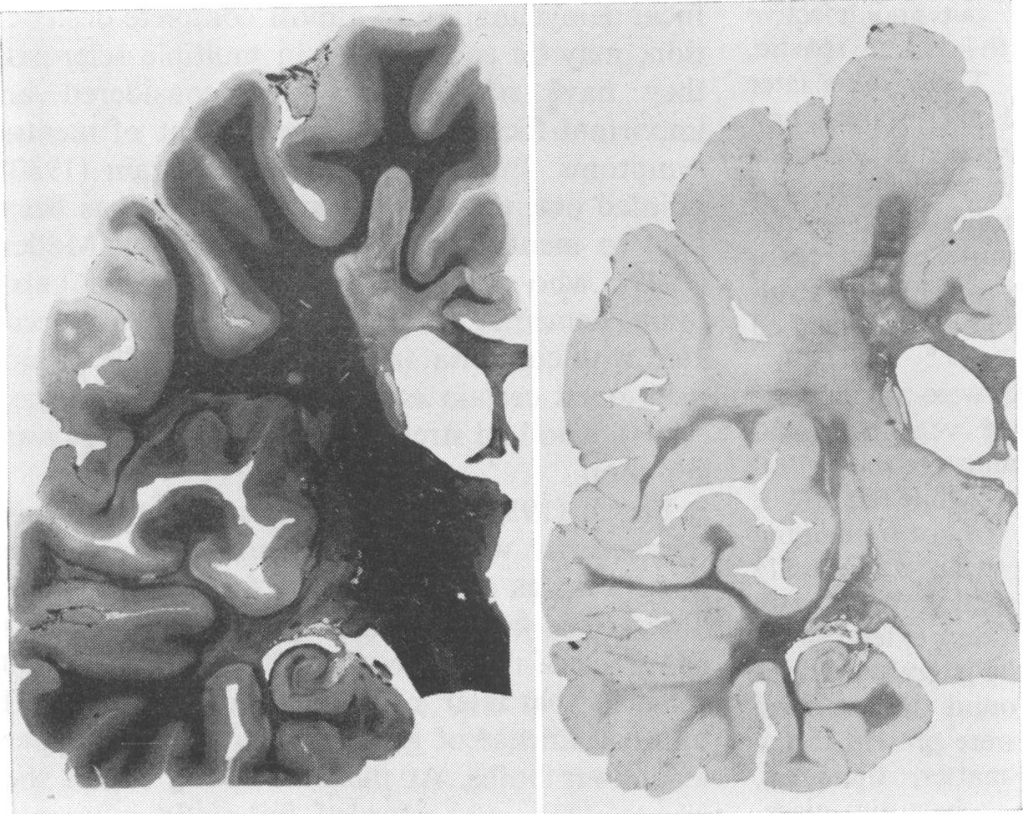

FIG. 2. Case 4. Section at the level of cornua Ammonis. There is dense gliosis in the temporal and insular white matter; in the periventricular plaques and their extensions superiorly into the frontal lobe; and in the corpus callosum. The ventricles are dilated. Heidenhain's myelin and Holzer's method for glial fibres, $\times 0 \cdot 8$.

on one occasion being shot when attempting escape, and from aerial bombardment. There was further trauma while on service with the Royal Air Force (1945-54).

On examination there was marked euphoria and he laughed inappropriately, without control. Memory for recent events was impaired and power of calculation defective. There was pallor of both optic

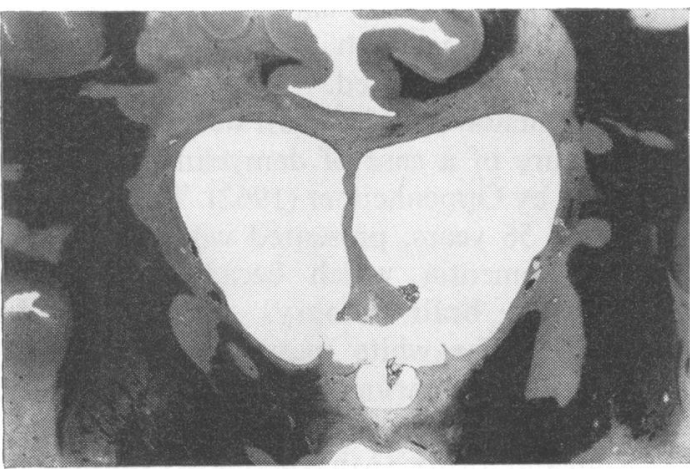

FIG. 3. Case 14. Demyelination of the corpus callosum. There are numerous oval or finger-like plaques in the periventricular white matter. Heidenhain's myelin, $\times 1 \cdot 0$.

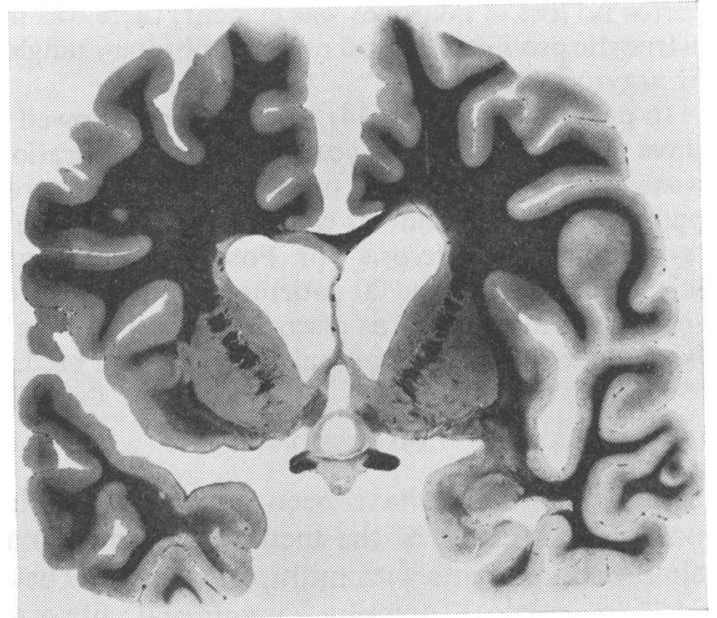

FIG. 4. Case 10. Section immediately behind the optic chiasm. Ventricular enlargement in a patient with 25 years' history. The corpus callosum is atrophied and is involved in two zones of periventricular demyelination. There are only a few tiny subcortical plaques and no overall white matter gliosis. Heidenhain's myelin, $\times 0 \cdot 6$. 
discs, slurring of speech, ataxia of gait, and defective joint position sense in the legs. Both legs were spastic, with extensor plantar responses. Three years later there were further signs of mental deterioration, and he was described as 'demented'. Despite incontinence of urine, flexor spasms of the legs, poor vision, and incomprehensible speech, he survived six further years. At postmortem examination excess cerebrospinal fluid was noted. There was moderate generalized thickening of leptomeninges. The brain weighed $1,178 \mathrm{~g}$.

The salient pathological findings were of moderate enlargement of lateral and third ventricles, and notable shrinkage of the corpus callosum, the central part of which was devoid of myelin, while laterally it was involved in plaques. Many of the remaining axons appeared normal, but some abnormally thickened axons and some retraction balls were present. Plaques of demyelination extended in conical form from the angles of the lateral ventricles and there was confluent loss around the temporal horns. Some small plaques also were present in the cortex and subcortical white matter, thalamus, putamen, globus pallidus, and substantia nigra. Holzer's method demonstrated a light gliosis of the regions of periventricular demyelination, but there was no overall gliosis of the white matter. Typical plaques were also present in the optic chiasm, around the fourth ventricle, in both inferior cerebellar peduncles and in the inferior olives. In the cerebral cortex no loss of neurones was evident; there was no astrocytic proliferation and no neurofibrillary tangles or argyrophile plaques.

In patients (nos $3,11,14)$ whose illness followed a short course (two to four years) mental deterioration was often an earlier and more prominent feature: pathologically the findings were closer to Marburg's 'acute multiple sclerosis' or Poser's 'transitional sclerosis'. None of the 20 patients in this series presented the features of a 'disconnection syndrome', but no special tests of callosal function were used.

\section{DISCUSSION}

Many possibilities have been advanced for the pathological basis of the mental and emotional changes in patients with multiple sclerosis. These include cortical atrophy, meningeal fibrosis, interruption of subcortical fibres in plaques, and thalamic or brain-stem involvement. The lesion underlying the characteristic euphoria has never been identified.

Although it is evident from the numerous published reports, and from the present series, that changes in the corpus callosum, varying from focal demyelination to almost complete destruction, may be encountered in multiple sclerosis, they have not usually been considered an important factor in the development of mentalo symptoms. Indeed, it may be, as Brain (1930) pointed out, that inadequate attention has been $\frac{\widehat{C}}{-}$ paid to mental changes in this disease. Müller (1949), who studied a large series of patients, found dementia of varying degree, often associ- $\overrightarrow{\vec{F}}$ ated with euphoria, in between 20 and $30 \%$, and $\stackrel{\text { ? }}{\circ}$ mentioned certain early authors, such as Geay $\frac{\square}{\sigma}$ (1904), who had stressed that mental change was common.

Bergin (1957) recorded two cases of multiple sclerosis in which rapidly progressive severe dementia was the outstanding feature of a short illness. The first patient, a woman aged 32 , had $\vec{\omega}$ an attack of retrobulbar neuritis at the age of 30 . years. A year later a second attack was followed by unsteadiness of gait and numbness of upper and lower limbs. At the time of admission sle was apathetic and retarded, but could cooperate. in question and answer; over the next threg $\vec{N}$ weeks her mental state deteriorated to severe do mentia. Pneumoencephalograms revealed mode ate symmetrical ventricular enlargement. After $a_{3}^{\circ}-$ short period of further deterioration she died. Postmortem examination revealed numeror plaques in the deep layers of the cortex and sul cortical white manner. No special mention made of the corpus callosum. The second $\overrightarrow{0}$ patient, a woman aged 24 years, presented with a similar history of rapidly progressive severe dementia with a prior episode of visual disturbance, and pneumoencephalograms showed ventricular dilatation with cortical atrophy. No necropsy was performed.

Severe mental deterioration was also a promi- $\overline{\mathrm{O}}$ nent feature of a case of demyelinating disease described by Oppenheimer (1962). The patient, $\mathrm{a}$ man aged 56 years, presented with slowly progressive dementia which became very much worse after brain biopsy. At postmortem: examination the white matter of the cerebral 3 . hemispheres was shrunken and discoloured and $\delta$ 'the most severe shrinkage was in the corpus callosum and fornix'. Microscopical examination 을 revealed diffuse lesions of partial or complete myelin loss in the cerebrum, sometimes with spongy rarefaction of tissue, and some small, $\tilde{N}$ well-defined, typical multiple sclerosis plaques. 
The author classified the case as an example of 'transitional sclerosis' with features of multiple sclerosis and of Schilder's disease.

McLardy and Sinclair (1964) recorded a case of 'presenile fulminating multiple sclerosis'. Their patient, a woman aged 60 years, died within six months of the onset of a dementing illness thought to be Alzheimer's disease on clinical grounds. There was extensive periventricular demyelination and numerous plaques in the cerebral hemispheres. Dilatation of the ventricles and thinning of the corpus callosum were present. These authors also noted a collapsed cyst in the pineal body and argued that structural changes in the suprapineal recess had resulted in excessive cerebrospinal fluid production. This, in turn, caused excessive intraventricular pressure and led to periventricular demyelination.

O'Malley (1966) reviewed existing accounts of dementia in multiple sclerosis and added three fresh cases with severe mental symptoms in which neuropathological study had shown some differences from the usual pattern of disease. There were large confluent areas of demyelination with gliosis, and axon destruction was often severe. The author considered such cases as being intermediate between Schilder's disease and multiple sclerosis, and associated the mental symptoms with the unusual extent of the lesions and the degree of destruction of tissue. In most respects these cases are comparable with cases 4 , 11 , and 14 of the present series.

McAlpine et al. (1972) considered that intellectual deterioration was rare in the early stages of the disease except for acute cases with widespread cerebral involvement. Apathy, loss of interest, irritability, poor memory, lack of concern for the future, sometimes associated with euphoria, were among the typical early symptoms of cerebral damage. He discussed the results of the various modern techniques for examining mental performance: in several reported series severe degrees of deterioration were found, but mainly in the chronic incapacitating stages of the disease.

It is evident that, while mental changes are a feature of some cases of multiple sclerosis, there are a number of possible mechanisms - cortical plaques, extensive white matter destruction and gliosis, hydrocephalus with, or without obstruc- tion-that may be responsible. It does not seem that a specific pattern of illness' is manifest that can be attributed with certainty to lesions of the corpus callosum. But our knowledge of the functions of this large interhemispheric commissure is still, in many ways, incomplete. A distinct 'corpus callosum syndrome' resulting from damage by tumour was proposed by Bristowe (1884) and elaborated by Ironside and Guttmacher (1929), but the value of these observations must be discounted to some extent, since tumours are seldom, if ever, confined to the corpus callosum. And the fact that in patients with chronic epilepsy section of the corpus callosum may not be followed by any dramatic sequelae has led some authors to postulate that it is a dispensable structure. These observations may be criticized, however, on the grounds that no suitably sensitive tests were applied to these subjects, and more recent work on man, in line with animal studies, has emphasized the importance of the corpus callosum in word-blindness and in the disconnection syndromes (Geschwind, 1965).

Marchiafava-Bignami's disease provides an example of demyelination affecting the corpus callosum in which mental changes are regularly found. This rare complication of chronic alcoholism is usually associated with an illness characterized by speech disorders and mental deterioration as prominent early signs, while stupor, convulsions, rigidity, and bilateral signs of pyramidal tract deficit may appear later (Ironside et al., 1961). The classical lesion is demyelination of the central part of the corpus callosum, amounting in some cases to cystic necrosis; in addition, the anterior commissure may be involved and occasionally the myelin loss extends to large portions of the hemispheric white matter (Castaigne et al., 1971).

Hydrocephalus is relatively common in multiple sclerosis. Freeman (1944) found ventricular dilatation, revealed by pneumoencephalography, in 11 out of 13 subjects. Similarly, Boudin et al. (1955) found ventricular dilatation in 30 out of their 33 patients, and in 15 it was marked Pathological studies vary in the proportion of cases affected: Zimmerman and Netsky (1950) examined 50 brains and found 'a mild degree of hydrocephalus' in many, but in only three was it 'unusually severe'. The cause remains obscure. 
Obstruction to the aqueduct by gliosis, obstruction to the fourth ventricle or its outlets by oedema of the brain-stem, cerebral atrophy due to shrinkage of white matter, and over-secretion of cerebrospinal fluid have all been proposed. Lumsden (1970) discounted the effects of shrinkage of tissue in plaques, and considered that 'those cases which do show appreciable secondary internal hydrocephalus will be found to be those in the later stages of the disease with an exceptional degree of axon loss'. Since it is usual, in cases of chronic multiple sclerosis, to find generalized thickening of leptomeninges with collagenous tissue, it is possible that changes in the arachnoidal villi are present, and impair their normal function, but we know of no evidence to support this.

The results of our own series emphasize the wide range of variation that typifies this disease. Ventricular enlargement may be marked after an illness of only short duration while in some chronic cases it is not found at all. A fair correlation can be made between callosal atrophy, hydrocephalus, and mental changes: none of the patients with small ventricles was recorded as showing signs of dementia. The value of our observations is limited, however, by the paucity of data concerning mental performance assessed by present techniques and because no special tests of corpus callosum function were employed.

Since changes similar in character and situation to those of Marchiafava-Bignami's disease are found in patients with multiple sclerosis, it is tempting to speculate that they may contribute to deterioration of mental function. It is clear that hydrocephalus is also an important factor.

We are indebted to the staff of The National Hospitals for Nervous Diseases for access to the clinical notes of their patients. We wish to thank Mrs Faith Rigby of the In-the-Ray Nursing Home for her cooperation. For helpful criticism we are grateful to Dr Douglas McAlpine and Professor W. H. McMenemey.

\section{REFERENCES}

Bergin, J. D. (1957). Rapidly progressing dementia in disseminated sclerosis. Journal of Neurology, Neurosurgery, and Psychiatry, 20, 285-292.

Boudin, G., Barbizet, J., and Mongermont (1955). Renseignements fournis par l'encéphalographie gazeuse au cours de la sclérose en plaques. Semaine des Hôpitaux de Paris, 31, 15-18.

Brain, W. R. (1930). Critical review; disseminated sclerosis. Quarterly Journal of Medicine, 23, 343-391.

Bristowe, J. S. (1884). Cases of tumour of the corpus callo- $\overparen{\mathbb{Q}}$ sum. Brain, 7, 315-333.

Castaigne, P., Buge, A., Cambier, J., Escourolle, R., and Rancurel, G. (1971). La maladie de Marchiafava-Bignami. Revue Neurologique, 125, 179-196.

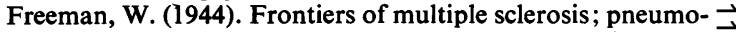
encephalography, electroencephalography, morbid anat- $\vec{\omega}$ omy and pathogenesis. Medical Annals of the District? of Columbia, January, 13, 1-10.

Geay, A. (1904). Troubles Psychiques dans la Sclérose en Plaques. A. Rey: Lyon.

Geschwind, N. (1965). Alexia and colour-naming distur市-. ance. In Functions of the Corpus Callosum, pp. 95-1 ב Edited by E. G. Ettlinger. Ciba Foundation Study Groug No. 20. Churchill: London.

Ironside, R., Bosanquet, F. D., and McMenemey, W. 息. (1961). Central demyelination of the corpus callosum (Marchiafava-Bignami disease). With report of a secosd case in Great Britain. Brain, 84, 212-230.

Ironside, R., and Guttmacher, M. (1929). The corpus callosum and its tumours. Brain, 52, 442-483.

Lumsden, C. E. (1970). The neuropathology of multipete sclerosis. In Handbook of Clinical Neurology, vol. 9, p. 217-309. Edited by P. J. Vinken and G. W. Bruyn. NorthHolland: Amsterdam.

McAlpine, D., Lumsden, C. E., and Acheson, E. D. (1972). Multiple Sclerosis. A Reappraisal. 2nd edn. ChurchillLivingstone: Edinburgh.

McLardy, T., and Sinclair, A. (1964). A case of presenile fulminating multiple sclerosis (with pathogenic considerations). Confinia Neurologica, 24, 417-424.

Müller, R. (1949). Studies on disseminated sclerosis. Acta Medica Scandinavica, 133, Suppl. 222.

O'Malley, P. P. (1966). Severe mental symptoms in disseminated sclerosis. A neuro-pathological study. Journal of the Irish Medical Association, 58, 115-124.

Oppenheimer, D. R. (1962). Observations on the Pathology of Demyelinating Diseases. D. M. Thesis: Oxford.

Zimmerman, H. M., and Netsky, M. G. (1950). The pathology of multiple sclerosis. Research Publication of the Association of Nervous and Mental Diseases, 28, 271-312. 